\title{
An Instagram-Based Study to Understand Betel Nut Use Culture in Micronesia: Exploratory Content Analysis
}

Wayne Buente ${ }^{1}, \mathrm{PhD}$; Francis Dalisay ${ }^{2}, \mathrm{PhD}$; Pallav Pokhrel ${ }^{3}, \mathrm{PhD}$; Hanae Kurihara Kramer ${ }^{1}, \mathrm{PhD}$; Ian Pagano ${ }^{3}, \mathrm{PhD}$

${ }^{1}$ School of Communications, University of Hawaii at Manoa, Honolulu, HI, United States

${ }^{2}$ Communication and Fine Arts Division, College of Liberal Arts \& Social Sciences, University of Guam, Mangilao, Guam

${ }^{3}$ Population Sciences in the Pacific Program (Cancer Prevention in the Pacific), University of Hawaii Cancer Center, University of Hawaii at Manoa, Honolulu, HI, United States

\section{Corresponding Author:}

Wayne Buente, $\mathrm{PhD}$

School of Communications

University of Hawaii at Manoa

2550 Campus Road

Crawford Hall

Honolulu, HI, 96822

United States

Phone: 18089563360

Email: wbuente@ hawaii.edu

\section{Abstract}

Background: A 2012 World Health Organization report recognizes betel nut use as an urgent public health threat faced by the Western Pacific region. However, compared with other addictive substances, little is known about how betel nuts are depicted on social media platforms. In particular, image-based social media platforms can be powerful tools for health communication. Studying the content of substance use on visual social media may provide valuable insights into public health interventions.

Objective: This study aimed to explore and document the ways that betel nut is portrayed on the photo-sharing site Instagram. The analysis focuses on the hashtag \#pugua, which refers to the local term for betel nut in Guam and other parts of Micronesia.

Methods: An exploratory content analysis of 242 Instagram posts tagged \#pugua was conducted based on previous research on substance use and Instagram and betel nut practices in Micronesia. In addition, the study examined the social engagement of betel nut content on the image-based platform.

Results: The study findings revealed content themes referencing the betel nut or betel nut tree, betel nut preparation practices, and the unique social and cultural context surrounding betel nut activity in Guam and Micronesia. In addition, certain practices and cultural themes encouraged social engagement on Instagram.

Conclusions: The findings from this study emphasize the cultural relevance of betel nut use in Micronesia. These findings provide a basis for empirically testing hypotheses related to the etiological roles of cultural identity and pride in shaping betel nut use behavior among Micronesians, particularly youths and young adults. Such research is likely to inform the development of culturally relevant betel nut prevention and cessation programs.

(J Med Internet Res 2020;22(7):e13954) doi: 10.2196/13954

\section{KEYWORDS}

betel nut; areca catechu; areca; cancer; health; Guam; Micronesia; Instagram; mobile phone; culture

\section{Introduction}

\section{Background}

Betel or areca nut is the fruit of a palm tree (Areca catechu) consumed as a psychostimulant by over 600 million people worldwide [1]. Betel nut chewing stretches from the African continent to the islands of Micronesia and has been prevalent since the dawn of recorded time [2]. Betel nut is enjoyed by both men and women as well as the young and old, often in combination with tobacco. Similar to other psychostimulants, betel nut chewing is known to cause a sense of euphoria, well-being, feelings of warmth, and increased capacity to work [3]. However, there are a number of health issues associated with betel nut consumption, most notably oral cancer [4]. 
Betel nut use is best understood as an orphan disease in the medical sense. It is consumed by non-Europeans in poor countries and under researched both in the West and in countries where it is endemic [5]. Increasingly, governments and health organizations are viewing betel nut chewing as a preventable threat to public health and a drain on medical resources.

In 2004, the International Agency for Research on Cancer classified the use of betel nut, with or without tobacco, as carcinogenic to human beings [6]. A 2012 World Health Organization report recognizes betel nut use as an urgent public health threat faced by the Western Pacific region, including Micronesia. Micronesia includes US territories such as the Northern Mariana Islands and Guam and island nations in free association with the United States, such as the Republic of Palau, Federated States of Micronesia, and the Republic of the Marshall Islands [7]. Cancer is 1 of the 2 leading causes of mortality in the US-Affiliated Pacific Islands (USAPI) [8,9]. Lung and oral cancer incidence and mortality rates are markedly higher in the USAPI than in the mainland United States [10].

Scholars have begun examining how social media platforms such as Facebook, Twitter, and YouTube contribute to alcohol use [11-13], smoking [14,15], and other health concerns [16,17]. Social media use in public health communication has been characterized as still in a wild west phase, where practitioners design and employ untested strategies [18], and the role of image-based social media platforms remains unexplored [19]. Systematic research is required to investigate how social media can be utilized to improve health communication.

As images are powerful tools of health communication [20], Instagram represents a unique social media platform that focuses on visual communication and the everyday ubiquity of smartphones. The use of betel nut in its various forms occurs throughout Southeast Asia and the Pacific Islands, where more than half of the world's mobile subscribers live [21]. A recent study found that betel nut content is trending on Instagram, with evidence of increasing user engagement [22]. Therefore, it is important to explore how betel nut use is depicted on an image-based social media platform such as Instagram.

\section{Use of Social Media to Understand Betel Nut Use}

Two theories that have been used to explain the uses and effects of social media include uses and gratifications (U\&G theory) [23] and social cognitive theory (SCT) [24]. As originally conceived, the $U \& G$ theory suggests that individuals are driven to use media to satisfy certain social and psychological needs, such as, among others, wanting to integrate themselves into society and escape the real world [25]. Recent studies have identified factors that may motivate individuals to use Instagram, including wanting to interact with others, archiving or documenting one's experiences, expressing oneself, escaping, and peeking or surveillance $[23,26]$. Such motives might also explain why individuals may choose to post betel nut-related content on Instagram.

On the other hand, SCT [27] posits that individuals can learn to adapt behaviors by modeling what they observe in the media. This assumption of SCT is consistent with the findings of recent studies, which indicate that as individuals are exposed to depictions of the use of a particular substance on social media, they become more likely to use the substance [28-30]. Using SCT as a framework may help understand how substance use behaviors are promoted on social media platforms [31]. Similarly, this study seeks to examine distinctions of betel nut-related content on Instagram to see how the social media platform may be used to promote betel nut use.

With 800 million users and 500 million users using the site daily, Instagram is the leading photo-sharing social media platform [32]. The majority (71\%) of Instagram users are aged between 18 and 24 years and visit Instagram daily, with 55\% using the platform several times a day [33]. As a networked visual social media platform, Instagram's images, videos, and interactive content engagement can have a notable impact on people's knowledge, attitudes, and perceptions of betel nut use. As Instagram is primarily a smartphone app, it is a technology that takes advantage of the portability and habitual use of mobile media [34]. As a result, the omnipresent nature of smartphones could offer a candid examination of betel nut practices within the everyday lives of its users. Furthermore, Instagram images and videos are uploaded and shared directly from a smartphone where other users interact with the content through likes and comments. The power of Instagram likes and comments has health implications, particularly among teenagers and young adults $[35,36]$.

\section{Depicting Substance Use on Instagram}

Instagram and similar image-sharing platforms have been the subject of several content analyses related to the promotion and use of addictive substances. For the most part, these studies favored visual over textual content utilizing topical hashtags to capture and document the context of individual use and marketing tactics undertaken on the platforms.

As a plant-based carcinogen, betel nut and betel quid have certain qualities that are similar to the marijuana plant. Instagram posts in marijuana-related hashtags showcased visual images of the marijuana plant [37]. Popular images included marijuana in its traditional forms (ie, buds and leaves) and nontraditional forms (ie, marijuana concentrates and marijuana-infused edibles). In addition, evidence of individuals using marijuana as well as marijuana-related advertisements demonstrated that marijuana content is prevalent on Instagram and helps to normalize and promote its use.

There is also evidence for the presence of hookah (water pipe) tobacco smoking content on visual social media platforms. Tumblr features prominent images of hookah pipes and smoke [38]. To a lesser degree, Tumblr also depicts the presence of waterpipe-related items such as hookah tobacco flavors, electronic hookahs, marijuana, alcohol, and tobacco products. Evidence of social gatherings, particularly between men and women, was also observed. Similarly, Instagram content using the hashtag \#hookah found images featuring individual waterpipe use, paraphernalia, and social gathering [39]. The presence of promotional material was prominent on Instagram and often cross-promoted alcohol use. In this regard, the marketing power of Instagram [40] may be well-suited to promote waterpipe use and nightlife entertainment. 
Recent studies have also documented electronic cigarettes (e-cigarettes) and vaping content on Instagram. In a dataset of 2208 Instagram images, the 3 most prominent themes were advertisements, products, and activity [41]. Advertisement themes explicitly promoted a commercial product and demonstrated the power of Instagram as a marketing tool. Activity themes showcased individuals exhaling aerosols, whereas product themes featured e-cigarettes or electronic juice (e-juice) bottles. An important finding is that likes and comments were found more with activity and product themes than with advertisement-themed images. Therefore, interactivity may prioritize particular Instagram content to larger audiences through social engagement on the platform [42]. A similar study considered e-cigarette visual content on both Instagram and Pinterest. Examining 1800 images from both image-based social media platforms, the popularity of marketing was evident, with $60 \%$ of Instagram posts devoted to marketing e-cigarettes. The second most common theme was customization, where users shared information about modifying e-cigarette devices for both functional and aesthetic purposes [43]. Product-related themes (ie, e-juice or flavors) were also evident. As Instagram is a very popular social media platform among teenagers, there is particular concern that Instagram postings may be especially attractive to youth, and that interest in flavors and juices will lure youth and others to try e-cigarettes.

Other health behaviors have been the subject of content analysis on Instagram. For example, a recent study examined the visual content of cigars and cigarillos on Instagram [44]. The findings indicated that Instagram promotes marijuana and tobacco use and promotion. In particular, Swisher products are used to promote the use of marijuana through blunt-making. Instagram images depicted individuals smoking little cigars and cigarillos as well as joints and blunts, though this was a less popular theme.

\section{Social and Cultural Characteristics of Betel Nut in the Western Pacific}

Chamorros inhabited the Mariana Islands, an archipelago located in the Western Pacific, when European explorers first arrived in 1521. The Chamorro word for betel nut is pugua. Although betel nut is known for its lexical diversity [5], it is the preferred term for betel nut among the various ethnicities of Guam. There are several ways to prepare betel nut for consumption, but 2 distinct practices have emerged in Guam and Micronesia. Betel nut may be chewed with slaked lime (afok) and betel pepper leaf (pupulu) in the form of a betel quid [45]. This is the most common and traditional preparation throughout the world [46] Peoples across Micronesia consume betel nut (typically unripened) in this way and spit out the juices as well as masticated quids [47]. However, most Chamorro chewers prefer mature nuts without lime and betel pepper leaves. Moreover, they ingest the juices and the betel nut itself [47]. In fact, Guam is the only island in Micronesia where people chew the mature areca nut [7].

Social and cultural motivations are prominent in the use of betel nut and prove difficult for sustaining health interventions [48,49]. Pugua represents Guam's social glue, the bond that builds and maintains social networks among Chamorros and
Micronesians [50]. It is shared among friends and family at weddings, anniversaries, and countless other social gatherings. Chewing betel nut is a habit that many Chamorros and Micronesians actively pass on to the next generation because it is a part of their heritage and is viewed as an important cultural identifier [47,51]. As a result, youth are continually exposed to betel nut practices leading to early onset of oral pathologies [46].

\section{Health and the Native Hawaiian and Pacific Islander Populations}

As an image-based social media platform with health implications, Instagram intersects with 3 important concerns for the Native Hawaiian and Pacific Islander (NHPI) population. In comparison with other groups, the NHPI population is young and increasing at a higher rate [52]. As teens and young adults increasingly move toward visual social media platforms [53-55], image-based platforms represent an important space for public health interventions that speak to the changing demographics in NHPI communities. Furthermore, adolescents and young adults consume betel nut, and social pressure is an important contributing factor for deciding to chew [56]. Second, few data are available for NHPI on health and wellness; however, there is much need to address inequalities in vital areas of NHPI community life [57]. All too often, NHPI population data are aggregated with other Asian American groups [52]. Finally, the NHPI population faces challenges in maintaining their unique languages and cultures. Previous research has shown that Pacific Islander communities value social media as a way to preserve culture and indigenous knowledge [58,59]. Betel nut use is closely tied to culture in Guam $[47,51,60,61]$ and throughout the USAPI $[62,63]$. All these denote important aspects for exploring how social media can promote health and behavioral change [64].

\section{The Goal of the Study}

This study is an attempt to explore the ways in which betel nut is depicted on the photo-sharing site Instagram. As an image-based social media platform, little is known about what betel nut content is depicted on Instagram. This leads to the first research question:

- Research Question 1: How is betel nut portrayed and represented on Instagram in Micronesia?

Instagram interactivity through user content may shape user perceptions and choices undertaken on the site. For this study, social media engagement takes the form of liking and commenting. Thus, the second research question is as follows:

- Research Question 2: How do Instagram users engage with Instagram's betel nut images and videos they encounter?

\section{Methods}

\section{Data Collection and Analysis}

To acquire Instagram content, Netlytic was employed as a cloud-based social media analytics tool [65]. Netlytic has been used to collect, analyze, and visualize social media data on a variety of research topics from political discussion on Twitter [66] to health care community practice [67]. On May 22, 2017, 
public Instagram posts tagged \#pugua were collected using the Instagram application programming interface (API) accessed through Netlytic. Data collection consisted of 284 Instagram posts dating back to 2011, uploaded by 180 unique Instagram users. A total of 4 posts were deleted from Instagram 1 month after data collection. All nonrelevant images and videos were also removed, resulting in a final dataset of 242 Instagram posts (234 images and 8 videos, 156 unique users). Figure 1 shows the number of posts identified and reasons for exclusion.

Figure 1. Inclusion of Instagram \#pugua posts and reasons for exclusion. E-cigarette: electronic cigarette.

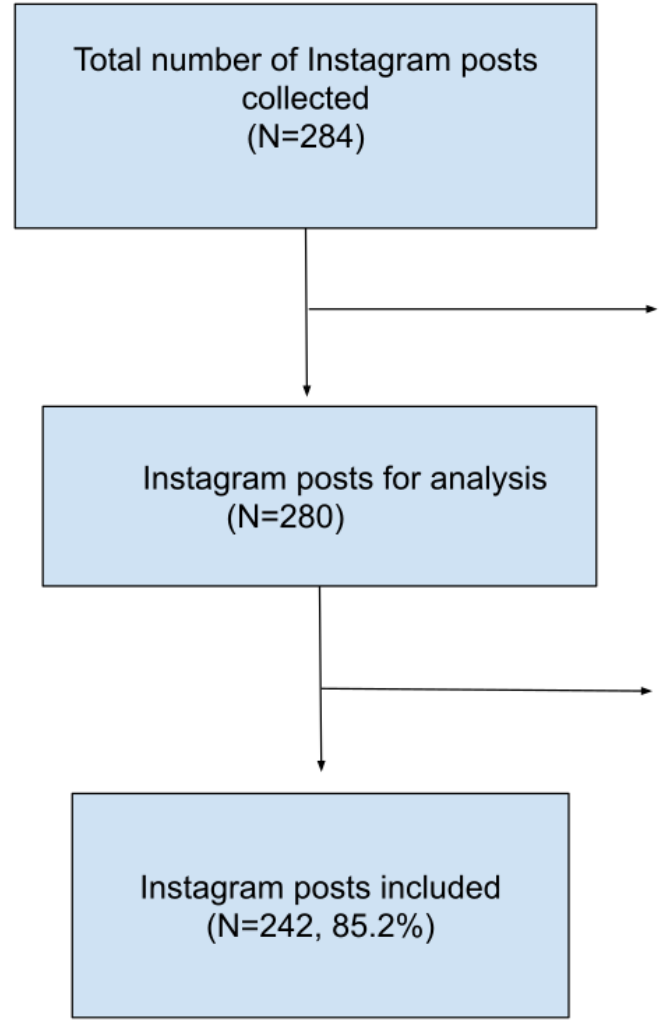

The unit of analysis was an Instagram post (metadata, image, caption, and comments). All images and videos were captured for data analysis. In addition, engagement was measured by adding the number of likes and comments for each post.

\section{Content Analysis}

A coding scheme was constructed based on prior content analysis studies on substance use and Instagram and the existing literature on betel nut use $[37,39,47]$. Images and videos were coded in content categories that addressed the type of betel nut depicted in the image and any paraphernalia present. This provided the category betel nut type that concerned the depiction of betel nut tree or leaves, betel nut paraphernalia, and the type of betel nut. The codebook accounts for 2 distinct practices between Chamorro betel nut preparation (mature nut) and non-Chamorro, Micronesian (Chuukese, Palauan, and Yapese) preparation (unripe nut with slaked lime and/or tobacco). Depictions of betel nut use formed an additional category, though later removed in pilot testing. Similar to marijuana, betel nut provides the medium for products and accessories such as jewelry and other consumer goods. Betel nut product advertisements were coded.

Drawing on the strong link between betel nut and Chamorro culture [47], the codebook accounted for the visual and textual depiction of Chamorro culture. In addition, posts that referenced island life in Guam were considered a separate category. Working through the data, stereotype accounted for the
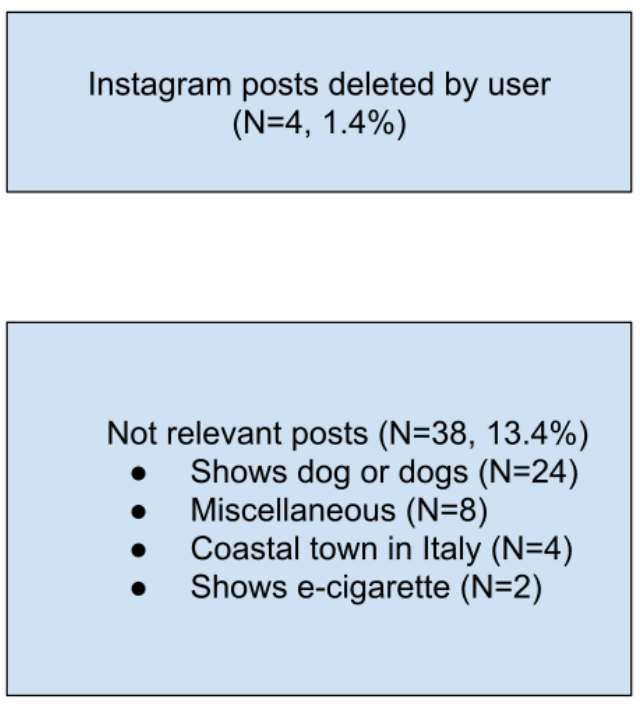

contentious use of betel nut by Micronesians in Guam [60]. All 3 categories were placed under an umbrella theme of cultural identifier.

Prior studies have shown that betel nut use has notable social characteristics, such as encouraging social acceptance and social meetings [47,51,68]. For example, a bag of betel nut can promote future social acceptance among peers through respect for tradition and social promotion [51]. In addition, betel nut is often brought as a gift or favor for celebrations and social meetings [47]. Two content categories documented social acceptance and promotion and social gathering. Social gathering was further divided into 2 subthemes for either celebration or social meeting.

Betel nut practices intertwine with familial relations. Thus, children and youth are exposed to betel nut at an early age. The initial codebook accounted for the presence of youth (ie, children, adolescents, or young adults) in image or video content. The last content category referenced traditional or independent media coverage of betel nut use.

For coding, images and videos can be placed in multiple content categories. For example, if an image depicted the betel nut tree ripe with betel nut, the image was coded to both betel nut tree or leaves and Yapese style (if Yapese-style betel nut was shown in the tree). If the image also included the presence of young 
children, the image would receive an additional code for children under youth presence.

To judge the effectiveness of the codebook, 2 student coders assessed a sample $(n=60)$ of the images and videos. A codebook with instructions and examples was created. After the first round of testing, codebook deficiencies led to improved content category definitions and the elimination of inadequate categorizations. For example, the depiction of betel nut use was difficult to detect in Instagram posts as it involves closed-mouth chewing. In addition, there were few perceived instances of betel nut chewing in the dataset, which were subsequently removed from the codebook.

A second round of interrater agreement was undertaken with a different set of more experienced coders. Utilizing their feedback on the coding instrument, a revised codebook was created, eliminating some content categories and improving the clarification of existing content categories. In all, 3 agreement measures demonstrated codebook validity: percentage concordance, Kappa $\alpha$, and Krippendorff $\alpha$. Given the multiple content categories and exploratory nature of the study, codebook concepts were considered reliable if percent agreement was $\geq 85 \%$, and reliability coefficients were 0.50 or higher. A total of 6 primary content categories produced favorable levels of interrater agreement (Multimedia Appendix 1). Subthemes found in the betel nut type, cultural identifier, and youth presence categories yielded acceptable levels of interrater agreement ranging from 0.57 (betel nut tree or leaves, $85 \%$ agreement) to 1.00 (cultural stereotype, $100 \%$ agreement).

\section{Results}

\section{Content Analysis}

To answer the first research question, the 242 Instagram posts produced 386 top-level codebook references using NVivo 11. Of these, betel nut type was the most frequent primary content category, yielding 209 references or $54.1 \%$ (209/386) of the coded content. As shown in Table 1, betel palm tree or leaves and Chamorro, or Yapese-style betel nut, represented the majority of content references $(182 / 209,87.1 \%)$. Many of the Chamorro $(56 / 64,88 \%)$ or Yapese-style $(34 / 48,71 \%)$ betel nut were in a prepared state ready for consumption. Betel nut paraphernalia (mainly betel nut cutters) was displayed in $12.4 \%$ $(26 / 209)$ of the referenced category content.

Table 1. Distribution of betel nut type categories $(\mathrm{N}=209)$.

\begin{tabular}{lc}
\hline Theme & References, $\mathrm{n}(\%)^{\mathrm{a}}$ \\
\hline Betel nut tree or leaves & $70(33.5)$ \\
Chamorro style nut & $64(30.6)$ \\
If Chamorro style nut, is it prepared? & $56(26.8)$ \\
Yapese style nut & $48(23.0)$ \\
If Yapese style nut, is it prepared? & $34(16.3)$ \\
Betel nut paraphernalia & $26(12.4)$ \\
\hline
\end{tabular}

${ }^{\text {a }}$ Percentages do not total to $100 \%$ because of the two conditional categories with their listed percentages.

The second most frequent content referenced on \#pugua was images and videos addressing various aspects of cultural identification. Cultural identification references accounted for $22.3 \%(86 / 386)$ of the coded data (Table 2). Of these, posts referencing visual and/or textual aspects of Chamorro culture represented more than half $(55 / 86,64 \%)$ of the content category. A total of $23 \%$ (20/86) of cultural content displayed elements of island life in Guam. As spitting has become a sign of racial tension on the island, the remaining content $(12 / 86,14 \%)$ depicted stereotypical images of Micronesian use of betel nut. This included images of red spittle on the ground or public no spitting signs, which serve as blatant racialized markers of tension between Chamorros and Micronesians.

Table 2. Distribution of cultural identification categories $(\mathrm{N}=86)$.

\begin{tabular}{ll}
\hline Theme & References, $\mathrm{n}(\%)$ \\
\hline Chamorro culture & $55(64)$ \\
Island life & $20(23)$ \\
Stereotype & $12(14)$ \\
\hline
\end{tabular}

Social acceptance and promotion comprised approximately $10.1 \%(39 / 386)$ of the dataset. As shown in Table 3, social acceptance and promotion included a bag or bags of betel nut. Youth presence $(\mathrm{N}=24)$ and betel nut product advertising $(\mathrm{N}=23)$ represented $6 \%$ of the overall content. Youth presence was equally split between children (aged 0-10 years) and adolescents (aged 11-17 years). Some Instagram posts showed children or adolescents handling betel nut in a playful manner. A total of 23 image or video references attempted to use \#pugua to sell or market betel nut products, clothing, or accessories. A total of 5 \#pugua Instagram posts depicted media coverage referencing documentaries addressing health concerns or the practice of betel nut chewing. 
Table 3. Distribution of social acceptance and promotion, youth presence, betel nut products and accessories, and media coverage categories $(\mathrm{N}=386)$.

\begin{tabular}{ll}
\hline Theme & References, $\mathrm{n}(\%)$ \\
\hline Social acceptance and promotion & $39(10.1)$ \\
Youth presence & $24(6.2)$ \\
Betel nut products and accessories & $23(6.0)$ \\
Media coverage & $5(1.3)$ \\
\hline
\end{tabular}

\section{Social Engagement in \#pugua}

The average engagement score (likes + comments) was 43.33 (SD 48.47) and displayed an upward trend (Figure 2).

To determine if particular \#pugua content related to social media engagement, engagement scores were classified into 3

Figure 2. Social media engagement on \#pugua $(\mathrm{N}=242)$.

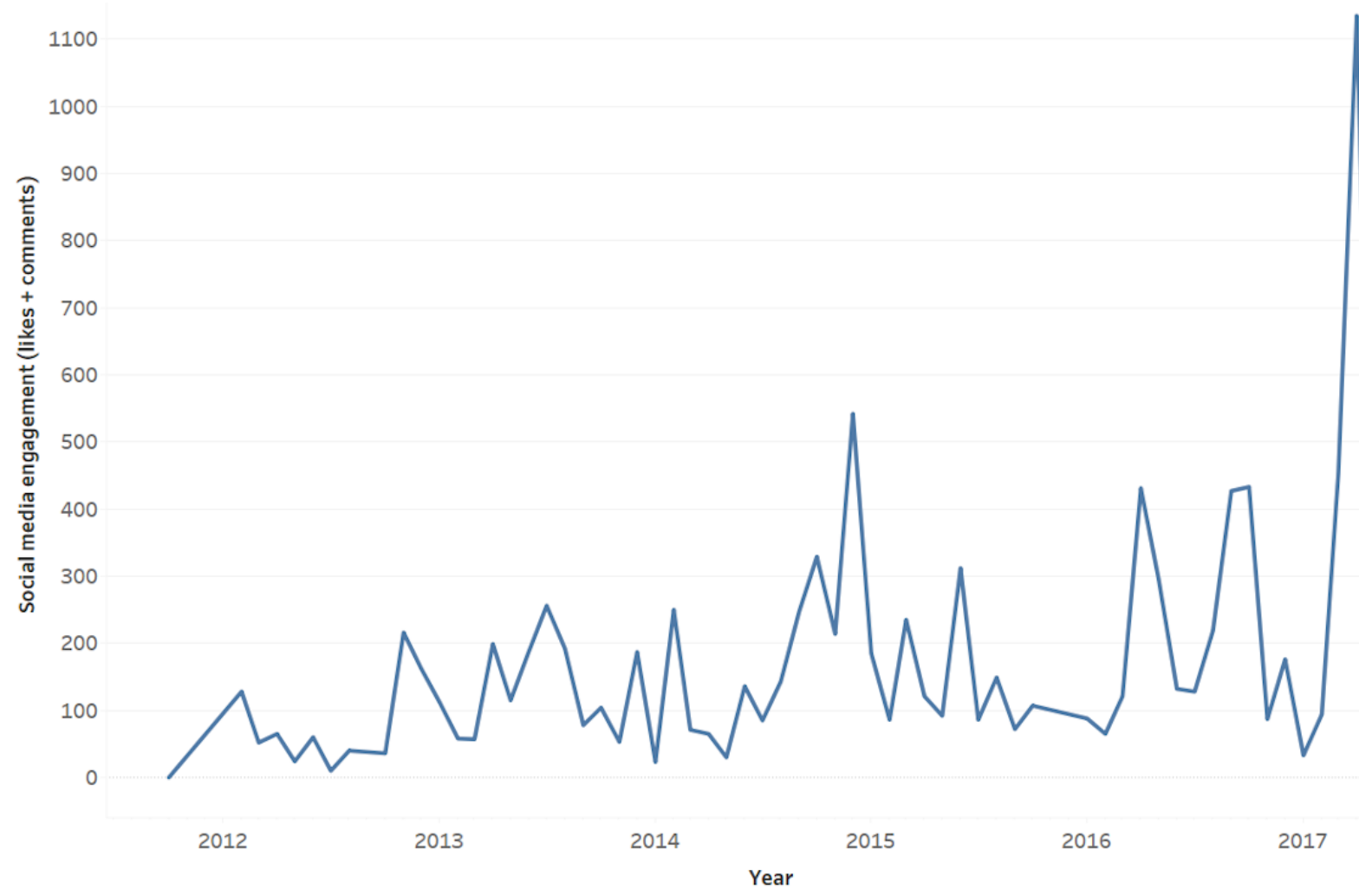

Table 4. Top 3 content categories by level of engagement.

\begin{tabular}{llll}
\hline Ranking & Low & Medium & High \\
\hline 1 & Chamorro-style betel nut (22) & Betel nut tree or leaves (35) & Chamorro culture (18) \\
2 & Betel nut tree or leaves (20) & Chamorro culture (30) & Chamorro-style betel nut (16) \\
3 & Yapese-style betel nut (17) & Chamorro-style betel nut (27) & Betel nut tree or leaves (15) \\
\hline
\end{tabular}

${ }^{\mathrm{a}}$ Numbers in parentheses indicate the frequency of the content category appearing in the matrix cell.

For the second research question, Instagram posts featuring betel nut tree or leaves (Figure 3) and Chamorro-style betel nut (Figure 4) consistently appear regardless of the level of social engagement. When Chamorro-style betel nut is shown, it is often in a prepared state. At the medium and high engagement level, 95\% (41/43) of the Chamorro-style betel nut posts showed betel nut in a Chamorro-prepared style (diced or cut). For low categories: low (0-18), medium (19-49), and high ( $\geq 50)$. Matrix coding resulted in 68 low engagement posts, 111 medium engagement posts, and 62 high engagement posts. For each engagement group, we ranked the 3 most frequent categories (Table 4). 
Figure 3. Artist's impression of a typical high engagement \#pugua image featuring a betel palm tree and mature betel nut. Illustration by Jessica $\mathrm{K}$ Sato.

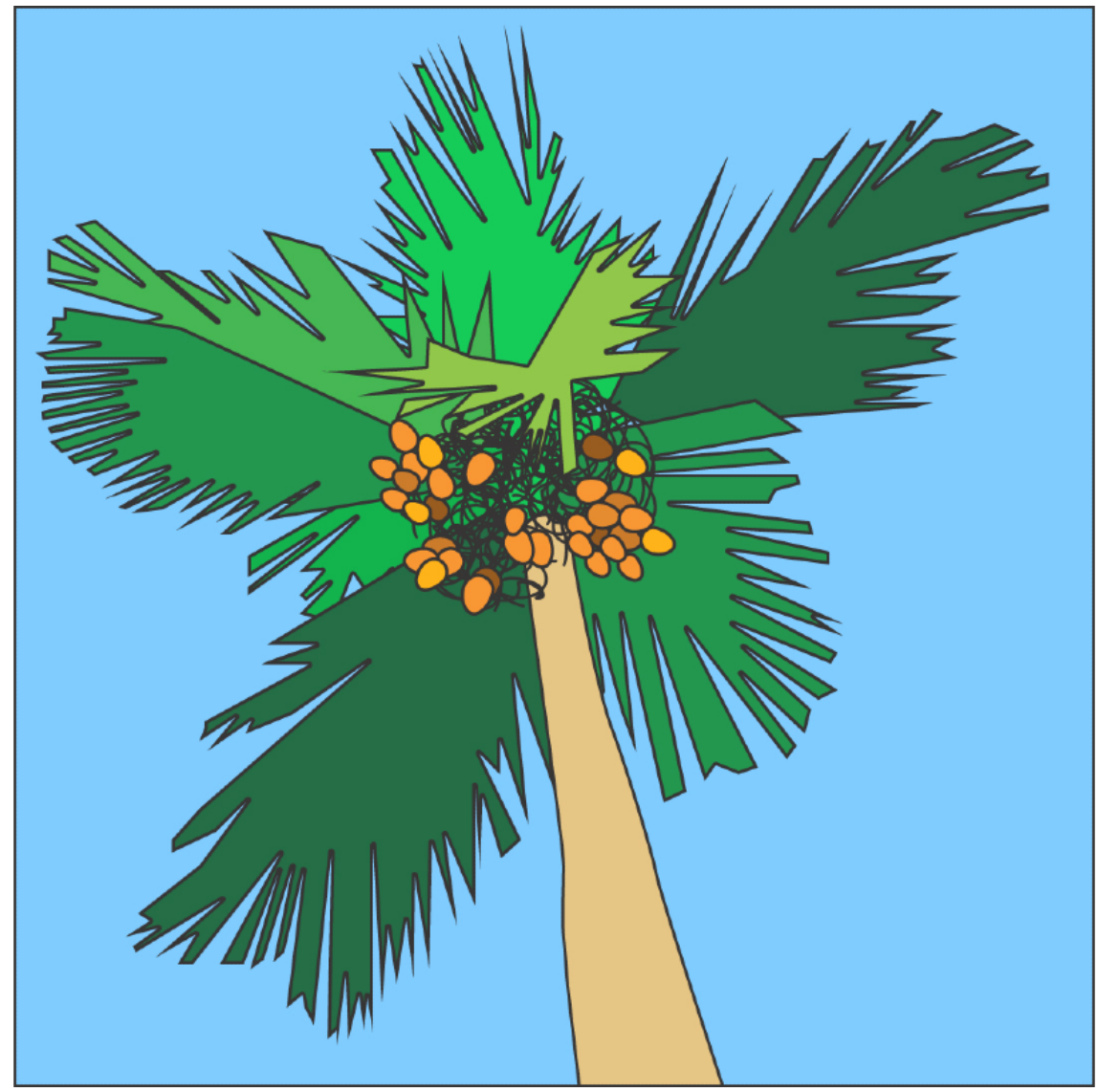

Figure 4. Artist's impression of a typical high engagement \#pugua image featuring mature betel nut, betel pepper leaves, slaked lime, and betel nut cutter. Illustration by Jessica K Sato.

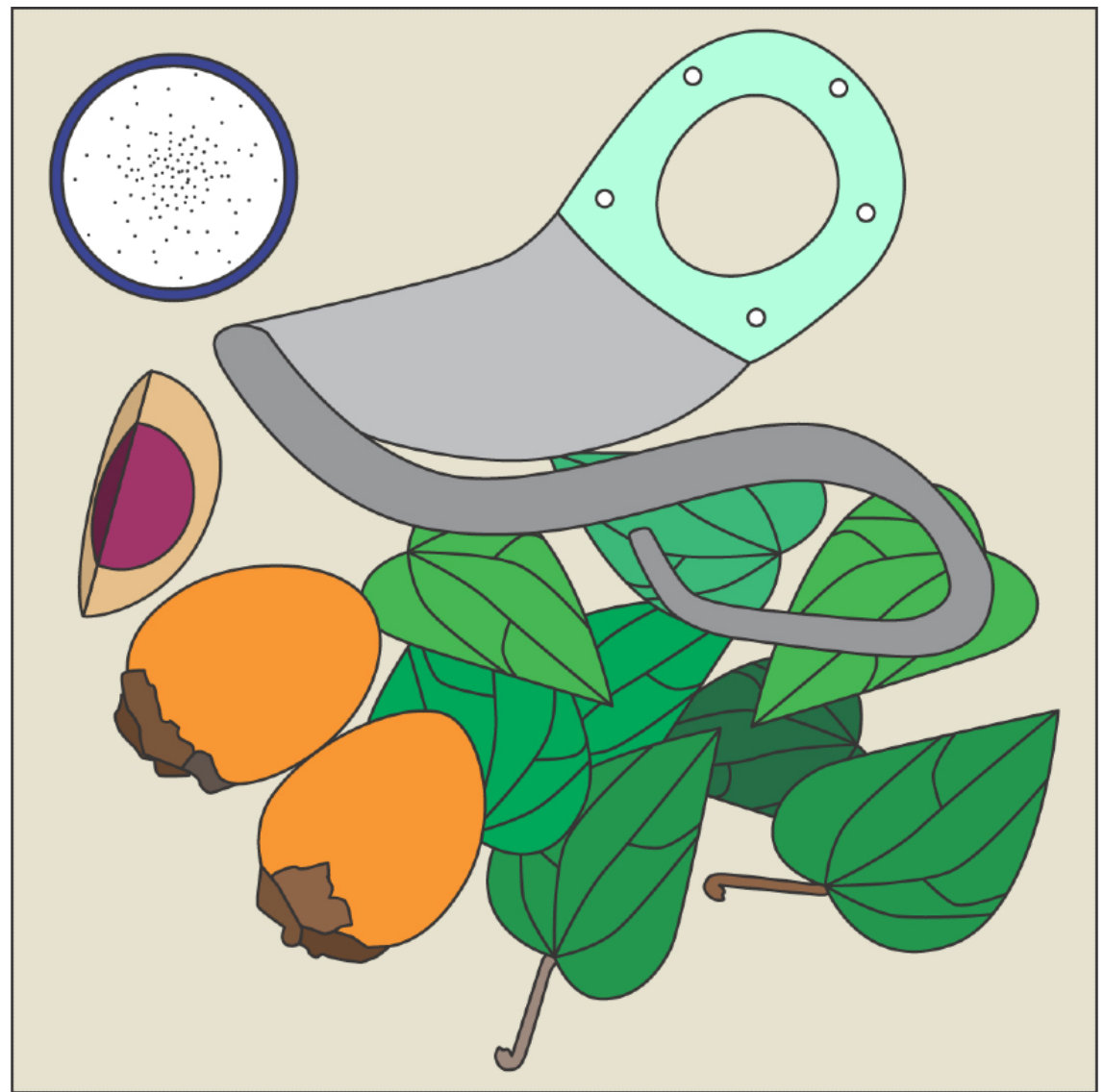




\section{Discussion}

\section{Principal Findings}

As shown in previous studies, betel nut use and practice vary by geographic region [69,70], and Guam is a unique case $[47,51,68]$. For Guam, betel nut chewing practices that are exhibited offline may replicate themselves on the web within the pugua hashtag. Prior evidence indicated 2 distinct betel nut chewing practices in Guam: Chamorro style and Yapese style [47]. Content analysis confirmed these 2 distinct preparation practices by noting the type of betel nut displayed (mature or unripe), as well as the distinct preparation practices before consumption. The Chamorro style prepares a mature betel nut that is often diced before consumption. In contrast, the Yapese style reflects Micronesian cultural preferences to consume an unripe nut with a piper betel leaf mixed with slaked lime or tobacco to form a betel quid. Aside from Instagram posts that featured betel nut tree or leaves, Chamorro- and Yapese-style betel nut and their respective preparation states were the most frequently occurring content in \#pugua. In addition, approximately $10 \%$ of Instagram posts showed betel nut cutters that slice betel nut for consumption. As a result, it is plausible that \#pugua users on Instagram have opportunities to observe how the betel nut moves from a whole nut to a chewable form. Further studies could determine if these visual depictions of betel nut cultural practices lead to greater uptake in betel nut use, especially among adolescents and young adults.

Approximately 1 out of every 5 \#pugua posts referenced Chamorro cultural content either through image/video, text, or both. Pugua has been referenced as the social glue for Chamorro culture. In the exploration of \#pugua, there were depictions of Chamorro culture such as dance, art, and festivals without the display of betel nut in the Instagram content. As prior work has demonstrated that Chamorros use social media to learn, capture, and preserve their culture [59], public health interventions should carefully consider how their visual messages link betel nut content on Instagram to Chamorro cultural identification.

\section{\#pugua and Social Engagement}

As Instagram is a visual social media platform, the circulation of the image through likes and comments may have more value than the image content [71]. The findings from this study determined that certain Instagram \#pugua posts had higher social engagement than others. Instagram \#pugua posts with moderate or high amounts of social engagement centered around visual content privileging Chamorro culture, Chamorro-style betel nut, and betel nut tree and leaves. Instagram and the smartphone favor in the moment sharing often reflecting everyday life instances. As betel nut use is an underexamined research phenomenon, there is a need to understand who, where, when, how, and why people chew betel nut [72]. The exploratory results of this study provide insights into the who, how, and why people in Guam and Micronesia chew betel nut and confirm the existing limited research in this area. Thus, this study represents a first step toward understanding how image-based social media platforms capture and collate information on betel nut practices.

\section{Comparison With Prior Work}

As a plant-based carcinogen, the areca nut and betel pepper leaf share certain qualities with the marijuana plant. These psychoactive plants provide facilities for ingesting and supplementing the use of the product. For example, betel nut may be consumed within the betel pepper leaf. Similarly, marijuana buds or leaves may be consumed or form additional use practices. Both plant-based products supply the medium for additional products and accessories. As a result, betel nut practice and use on Instagram may closely resemble the practice and use of marijuana on Instagram. Comparing the study's findings with the large-scale work on marijuana and Instagram [37], there are some similarities, but also notable differences.

As indicated by previous research on marijuana and Instagram [37], the most frequent Instagram posts involved showing the betel palm tree and leaves, mature or unripe betel nut, and its various consumption practices. In this regard, the betel nut and marijuana plant share certain visual characteristics that appeal to their respective audiences on Instagram. Therefore, public health professionals should consider how to balance appealing visual content with helpful information for young people about the known risks of betel nut use.

The consumption and masticatory use of betel nut did not appear to be compelling content on Instagram. Very few Instagram posts featured chewing of betel nut or betel quid. If it was displayed, it was only through a closed mouth where a lump could be witnessed in the person's jaw. Previous studies have shown that betel nut chewing and spitting are bad habits that undermine public health [73]. On a visual communication medium such as Instagram, it is difficult to portray betel nut chewing as novel and interesting to facilitate social networking. This finding is in contrast to the work done on the use of marijuana in social media $[37,74]$. Previous research has shown that marijuana use on social media facilitates social networking about marijuana, particularly among young adults and underage youth. Ingesting marijuana in its traditional plant-based and novel forms (edibles and concentrates) is perhaps more visually appealing and also helps to normalize and promote marijuana use as a form of practice. Similarly, e-cigarette, hookah, and cigar/cigarillos Instagram content featured activity and use themes such as smoking, exhaling clouds, and smoke tricks $[38,39,41,43,44]$. The exploratory findings in this study did not observe the use of betel nut on an image-based social media platform.

Advertising and marketing tactics have been well documented for e-cigarette and marijuana use on Instagram [30,37,41]. However, there was little evidence of advertising and product promotion of betel nut in \#pugua. This is most likely a reflection of the lack of a clear marketplace that sells specific accessories and products related to its consumption, such as vape shops and marijuana dispensaries. Betel nut products that were advertised tended toward clothing or jewelry accessories made from betel palm tree or pepper leaf fibers. These Instagram posts are often linked to specific references to Chamorro culture. Therefore, it is plausible that \#pugua on Instagram functions less as a marketplace and more as a cultural space. 


\section{Limitations}

There are limitations to this study. The dataset was small and limited the generalizability of the study findings. A paid Netlytic account captured all posts that met the inclusion criteria. Given the size of the dataset, all \#pugua posts were analyzed, and there was no sampling required. However, data collection and sampling remain a challenge for capturing image-based social media content because of API restrictions and privacy concerns [19]. Algorithms on Instagram also influence the visibility of the \#pugua content [75] and certainly contribute toward its social engagement. Nonetheless, caution should be exercised to avoid generalizing the findings of \#pugua to all Instagram users and contexts. Future work should empirically test the study's implications through experiments documenting image content effects on Instagram betel nut users or pursue large-scale data collection of \#betelnut and regional betel nut terms as hashtags on social media platforms.

\section{Conclusions}

This study analyzed the ways in which betel nut is depicted on the photo-sharing site Instagram. A content analysis of \#pugua explored betel nut practices in \#pugua and its engagement on the platform. The study findings suggest that betel nut preparation practices reflect offline practices in Guam and Micronesia. In addition, socially engaged content is more likely to reflect the areca nut, betel palm tree or leaves and Chamorro cultural sensibilities. Compared with prior work on substance use and Instagram, \#pugua content demonstrated similarities to marijuana in terms of depicting the betel palm tree, areca nut, and quid ingredients. In addition, advertisements of betel nut clothing and accessories were observed. In contrast to prior work, there was little evidence of actual betel nut use and consumption, which is typically a prominent feature in marijuana, hookah, and vaping content on image-based social media.

The findings from this study emphasize the cultural relevance of betel nut use in Micronesia. The findings provide a basis for empirically testing hypotheses related to the etiological roles of cultural identity and pride in shaping betel nut use behavior among Micronesians, particularly youths and young adults. Such research is likely to inform the development of culturally relevant betel nut prevention and cessation programs.

\section{Acknowledgments}

The authors would like to acknowledge the U54 University of Guam (National Institutes of Health [NIH] Grant 1U54CA143728)/University of Hawaii Cancer Center Partnership (NIH Grant 1U54CA143727) for their support. The authors would also like to thank Dr Lala Hajibayova, Mallory McCorkhill, Hannah Mettias, and Lauren Muraoka for their valuable assistance with our research project. We are very grateful to freelance designer and strategist Jessica K Sato for her artist illustrations.

\section{Conflicts of Interest}

None declared.

\section{Multimedia Appendix 1}

Reliability indicators for codebook categories.

[DOCX File, 18 KB-Multimedia Appendix 1]

\section{References}

1. Boucher BJ, Mannan N. Metabolic effects of the consumption of Areca catechu. Addict Biol 2002 Jan;7(1):103-110. [doi: 10.1080/13556210120091464] [Medline: 11900629]

2. Haddock RL, Hoffman JH, Williams WR. Betel nut chewing in Guam. Fiji Med J 1981;9(8/9):139-149.

3. Oliver D, Johnson L. Oceania: The Native Cultures of Australia and the Pacific Islands. Honolulu, HI: University of Hawaii Press; 1989.

4. Hernandez BY, Bordallo RA, Green MD, Haddock RL. Cancer in Guam and Hawaii: a comparison of two US island populations. Cancer Epidemiol 2017 Oct;50(Pt B):199-206 [FREE Full text] [doi: 10.1016/j.canep.2017.08.005] [Medline: 29120826]

5. Osborne PG, Ko Y, Wu M, Lee C. Intoxication and substance use disorder to Areca catechu nut containing betel quid: a review of epidemiological evidence, pharmacological basis and social factors influencing quitting strategies. Drug Alcohol Depend 2017 Oct 1;179:187-197. [doi: 10.1016/j.drugalcdep.2017.06.039] [Medline: 28787696]

6. IARC Working Group on the Evaluation of Carcinogenic Risks to Humans. Betel-Quid and Areca-Nut Chewing and Some Areca-Nut-Derived Nitrosamines. Lyon, France: World Health Organization; 2004.

7. World Health Organization. Review of Areca ( Betel) Nut and Tobacco Use in the Pacific: A Technical Report. Geneva, Switzerland: World Health Organization; 2012.

8. Guam Comprehensive Cancer Control Plan 2013-2017. Centers for Disease Control and Prevention. 2013. URL: ftp://ftp. cdc.gov/pub/Publications/Cancer/ccc/guam ccc plan.pdf [accessed 2019-03-01] 
9. Cancer in the US Affiliated Pacific Islands 2007-2012. Pacific Cancer Programs. 2015. URL: http://www.pacificcancer.org/ site-media/docpdfonwebpage/2015/PIJ\%20Cancer\%20Facts\&\%20Figures\%202007-2012\%20060115.pdf [accessed 2020-06-05]

10. Pacific Regional Comprehensive Cancer Control Plan 2007-2012. Centers for Disease Control and Prevention. 2007. URL: ftp://ftp.cdc.gov/pub/Publications/Cancer/ccc/pacific regional ccc plan 2007 2012.pdf [accessed 2019-03-04]

11. Beullens K, Schepers A. Display of alcohol use on Facebook: a content analysis. Cyberpsychol Behav Soc Netw 2013 Jul;16(7):497-503. [doi: 10.1089/cyber.2013.0044] [Medline: 23617225]

12. Erevik EK, Torsheim T, Vedaa O, Andreassen CS, Pallesen S. Sharing of alcohol-related content on social networking sites: frequency, content, and correlates. J Stud Alcohol Drugs 2017 May;78(4):608-616. [doi: 10.15288/jsad.2017.78.608] [Medline: 28728643]

13. Sampasa-Kanyinga H, Chaput J. Use of social networking sites and alcohol consumption among adolescents. Public Health 2016 Oct;139:88-95. [doi: 10.1016/j.puhe.2016.05.005] [Medline: 27311992]

14. Myslín M, Zhu S, Chapman W, Conway M. Using Twitter to examine smoking behavior and perceptions of emerging tobacco products. J Med Internet Res 2013 Aug 29;15(8):e174 [FREE Full text] [doi: 10.2196/jmir.2534] [Medline: 23989137]

15. Phua J. Participating in health issue-specific social networking sites to quit smoking: how does online social interconnectedness influence smoking cessation self-efficacy? J Commun 2013 Sep 16;63(5):933-952. [doi: 10.1111/jcom.12054]

16. Fung IC, Blankenship EB, Goff ME, Mullican LA, Chan KC, Saroha N, et al. Zika-virus-related photo sharing on Pinterest and Instagram. Disaster Med Public Health Prep 2017 Dec;11(6):656-659. [doi: 10.1017/dmp.2017.23] [Medline: 28330514]

17. Seltzer EK, Horst-Martz E, Lu M, Merchant RM. Public sentiment and discourse about Zika virus on Instagram. Public Health 2017 Sep;150:170-175. [doi: 10.1016/j.puhe.2017.07.015] [Medline: 28806618]

18. Ems L, Gonzales AL. Subculture-centered public health communication: a social media strategy. New Media Soc 2016 Jul 10;18(8):1750-1767. [doi: 10.1177/1461444815570294]

19. Fung IC, Blankenship EB, Ahweyevu JO, Cooper LK, Duke CH, Carswell SL, et al. Public health implications of image-based social media: a systematic review of Instagram, Pinterest, Tumblr, and Flickr. Perm J 2020;24:- [FREE Full text] [doi: 10.7812/TPP/18.307] [Medline: 31852039]

20. Houts PS, Doak CC, Doak LG, Loscalzo MJ. The role of pictures in improving health communication: a review of research on attention, comprehension, recall, and adherence. Patient Educ Couns 2006 May;61(2):173-190. [doi: 10.1016/j.pec.2005.05.004] [Medline: 16122896]

21. The Mobile Economy: Asia Pacific 2018. GMSA Intelligence. 2018. URL: https://www.gsma.com/asia-pacific/resources/ the-mobile-economy-asia-pacific-2018/ [accessed 2019-05-31]

22. Buente W, Rathnayake C, Neo R, Dalisay F, Kramer H. Tradition gone mobile: an exploration of \#betelnut on Instagram. Subst Use Misuse 2020;55(9):1483-1492. [doi: 10.1080/10826084.2020.1744657]

23. Sheldon P, Bryant K. Instagram: motives for its use and relationship to narcissism and contextual age. Comput Human Behav 2016 May;58:89-97. [doi: 10.1016/j.chb.2015.12.059]

24. Khang H, Han E, Ki E. Exploring influential social cognitive determinants of social media use. Comput Human Behav 2014 Jul;36:48-55. [doi: 10.1016/j.chb.2014.03.038]

25. Katz E, Haas H, Gurevitch M. On the use of the mass media for important things. Am Sociol Rev 1973 Apr;38(2):164. [doi: 10.2307/2094393]

26. Lee E, Lee J, Moon JH, Sung Y. Pictures speak louder than words: motivations for using Instagram. Cyberpsychol Behav Soc Netw 2015 Sep;18(9):552-556. [doi: 10.1089/cyber.2015.0157] [Medline: 26348817]

27. Bandura A. Social cognitive theory of mass communication. Media Psychol 2001 Aug;3(3):265-299. [doi: 10.1207/S1532785XMEP0303 03]

28. Depue JB, Southwell BG, Betzner AE, Walsh BM. Encoded exposure to tobacco use in social media predicts subsequent smoking behavior. Am J Health Promot 2015;29(4):259-261. [doi: 10.4278/ajhp.130214-ARB-69] [Medline: 24670071]

29. Nesi J, Rothenberg WA, Hussong AM, Jackson KM. Friends' alcohol-related social networking site activity predicts escalations in adolescent drinking: mediation by peer norms. J Adolesc Health 2017 Jun;60(6):641-647 [FREE Full text] [doi: 10.1016/j.jadohealth.2017.01.009] [Medline: 28325545]

30. Pokhrel P, Fagan P, Herzog TA, Laestadius L, Buente W, Kawamoto CT, et al. Social media e-cigarette exposure and e-cigarette expectancies and use among young adults. Addict Behav 2018 Mar;78:51-58 [FREE Full text] [doi: 10.1016/j.addbeh.2017.10.017] [Medline: 29127784]

31. Kong G, LaVallee H, Rams A, Ramamurthi D, Krishnan-Sarin S. Promotion of vape tricks on YouTube: content analysis. J Med Internet Res 2019 Jun 18;21(6):e12709 [FREE Full text] [doi: 10.2196/12709] [Medline: 31215510]

32. Systrom K. Strengthening Our Commitment to Safety and Kindness for 800 Million. Instagram Press. 2017. URL: https:/ /instagram-press.com/blog/2017/09/26/strengthening-our-commitment-to-safety-and-kindness-for-800-million/ [accessed 2019-02-25]

33. Smith A, Anderson M. Social Media Use in 2018. Pew Research Center. 2018. URL: http://www.pewinternet.org/2018/ 03/01/social-media-use-in-2018/ [accessed 2019-02-28] 
34. Schrock A. Communicative affordances of mobile media: portability, availability, locatability, and multimediality. Int J Commun 2015;9:1229-1246 [FREE Full text]

35. Butkowski CP, Dixon TL, Weeks K. Body surveillance on Instagram: examining the role of selfie feedback investment in young adult women's body image concerns. Sex Roles 2019;81(5-6):385-397. [doi: 10.1007/s11199-018-0993-6]

36. Sherman LE, Payton AA, Hernandez LM, Greenfield PM, Dapretto M. The power of the like in adolescence: effects of peer influence on neural and behavioral responses to social media. Psychol Sci 2016 Jul;27(7):1027-1035 [REEE Full text] [doi: 10.1177/0956797616645673] [Medline: 27247125]

37. Cavazos-Rehg PA, Krauss MJ, Sowles SJ, Bierut LJ. Marijuana-related posts on Instagram. Prev Sci 2016 Aug;17(6):710-720 [FREE Full text] [doi: $\underline{10.1007 / \mathrm{s} 11121-016-0669-9}$ ] [Medline: 27262456]

38. Primack BA, Carroll MV, Shensa A, Davis W, Levine MD. Sex differences in hookah-related images posted on Tumblr: a content analysis. J Health Commun 2016;21(3):366-375 [FREE Full text] [doi: 10.1080/10810730.2015.1095814] [Medline: 26890733]

39. Allem J, Chu K, Cruz TB, Unger JB. Waterpipe promotion and use on Instagram: \#hookah. Nicotine Tob Res 2017 Oct 1;19(10):1248-1252 [FREE Full text] [doi: 10.1093/ntr/ntw329] [Medline: 28077449]

40. Carah N. Algorithmic brands: a decade of brand experiments with mobile and social media. New Media Soc 2017;19(3):384-400. [doi: 10.1177/1461444815605463]

41. Chu K, Allem J, Cruz TB, Unger JB. Vaping on Instagram: cloud chasing, hand checks and product placement. Tob Control 2016 Sep;26(5):575-578 [FREE Full text] [doi: 10.1136/tobaccocontrol-2016-053052] [Medline: 27660111]

42. Carah N, Shaul M. Brands and Instagram: point, tap, swipe, glance. Mob Media Commun 2016;4(1):69-84. [doi: $10.1177 / 2050157915598180]$

43. Lee AS, Hart JL, Sears CG, Walker KL, Siu A, Smith C. A picture is worth a thousand words: electronic cigarette content on Instagram and Pinterest. Tob Prev Cessat 2017 Jul;3:- [FREE Full text] [doi: 10.18332/tpc/74709] [Medline: 28815224]

44. Allem J, Escobedo P, Chu K, Cruz TB, Unger JB. Images of little cigars and cigarillos on Instagram identified by the hashtag \#swisher: thematic analysis. J Med Internet Res 2017 Jul 14;19(7):e255 [FREE Full text] [doi: 10.2196/jmir.7634] [Medline: 28710057]

45. Cunningham L. Ancient Chamorro Society. Honolulu, HI: The Bess Press; 1992.

46. Winstock A. Areca nut, betel quids and associated products. In: Miller PM, editor. Principles of Addiction: Comprehensive Addictive Behaviors and Disorders. Volume 1. San Diego, CA: Academic Press; 2013:863-872.

47. Murphy KL, Herzog TA. Sociocultural factors that affect chewing behaviors among betel nut chewers and ex-chewers on Guam. Hawaii J Med Public Health 2015 Dec;74(12):406-411 [FREE Full text] [Medline: 26668772]

48. Little MA, Pokhrel P, Murphy KL, Kawamoto CT, Suguitan GS, Herzog TA. The reasons for betel-quid chewing scale: assessment of factor structure, reliability, and validity. BMC Oral Health 2014 Jun 3;14:62 [FREE Full text] [doi: 10.1186/1472-6831-14-62] [Medline: 24889863]

49. Sotto PP, Mendez AJ, Herzog TA, Cruz C, Chennaux JS, Legdesog C, et al. Barriers to quitting Areca nut consumption and joining a cessation program as perceived by chewer and nonchewer populations in Guam. Subst Use Misuse 2020;55(6):947-953. [doi: 10.1080/10826084.2020.1716012] [Medline: 31973623 ]

50. Diaz V. Simply Chamorro: tales of demise and survival in Guam. In: Borofsky R, editor. Remembrance of Pacific Pasts: An Invitation to Remake History. Honolulu: University of Hawaii Press; 2000:362-382.

51. Paulino YC, Novotny R, Miller MJ, Murphy SP. Areca (betel) nut chewing practices in micronesian populations. Hawaii J Public Health 2011 Mar;3(1):19-29 [FREE Full text] [Medline: 25678943]

52. Kana'iaupuni SM. Lots of aloha, little data: data and research on native Hawaiian and pacific islanders. AAPI Nexus 2011 Sep;9(1-2):207-211. [doi: 10.17953/appc.9.1-2.k154x5g4711j984m]

53. Anderson M, Jiang J. Teens, Social Media \& Technology 2018. Pew Research Center. 2018. URL: http://www. pewinternet.org/2018/05/31/teens-social-media-technology-2018/ [accessed 2019-06-01]

54. Sarkar U, Le GM, Lyles CR, Ramo D, Linos E, Bibbins-Domingo K. Using social media to target cancer prevention in young adults: viewpoint. J Med Internet Res 2018 Jun 5;20(6):e203 [FREE Full text] [doi: 10.2196/jmir.8882] [Medline: $\underline{29871850}]$

55. Villanti AC, Johnson AL, Ilakkuvan V, Jacobs MA, Graham AL, Rath JM. Social media use and access to digital technology in US young adults in 2016. J Med Internet Res 2017 Jun 7;19(6):e196 [FREE Full text] [doi: 10.2196/jmir.7303] [Medline: 28592394]

56. Pokhrel P, Dalisay F, Pagano I, Buente W, Guerrero E, Herzog TA. Adolescent tobacco and betel nut use in the US-affiliated pacific islands: evidence from Guam. Am J Health Promot 2019 Sep;33(7):1058-1062 [FREE Full text] [doi: 10.1177/0890117119847868] [Medline: 31117807 ]

57. Hune S, Kagawa-Singer M. Closing the research and data gap in order to serve Asian Americans and pacific islanders better. AAPI Nexus 2011 Sep;9(1-2):vii-xii. [doi: 10.17953/appc.9.1-2.qmmw65040n774036]

58. Diettrich B. Virtual Micronesia: performance and participation in a pacific Facebook community. Perfect Beat 2016 Mar 31;17(1):52-70. [doi: 10.1558/prbt.v17i1.28841]

59. San Nicolas-Rocca T, Parrish J. Capturing and conveying Chamorro cultural knowledge using social media. International Journal of Knowledge Management 2013;9(3):1-18. [doi: 10.4018/ijkm.2013070101] 
60. Hattori AP. Betel mania, from culture to cancer: digestive and discursive uses of the betel nut (areca catechu) in Guam. Pac Stud 2018;41(3):199-223.

61. Moss J, Kawamoto C, Pokhrel P, Paulino Y, Herzog T. Developing a betel quid cessation program on the island of Guam. Pac Asia Inq 2015;6(1):144-150 [FREE Full text] [Medline: 27057560]

62. Griffin MT, Mott M, Burrell PM, Fitzpatrick JJ. Palauans who chew betel nut: social impact of oral disease. Int Nurs Rev 2014 Mar;61(1):148-155. [doi: 10.1111/inr.12082] [Medline: 24512263]

63. Paulino YC, Ettienne R, Novotny R, Wilkens LR, Shomour M, Sigrah C, et al. Areca (betel) nut chewing practices of adults and health behaviors of their children in the freely associated states, micronesia: findings from the children's healthy living (CHL) program. Cancer Epidemiol 2017 Oct;50(Pt B):234-240. [doi: 10.1016/j.canep.2017.07.009] [Medline: 29120830]

64. Korda H, Itani Z. Harnessing social media for health promotion and behavior change. Health Promot Pract 2013 Jan;14(1):15-23. [doi: 10.1177/1524839911405850] [Medline: 21558472]

65. Gruzd A, Mai P, Kampen A. A how-to for using Netlytic to collect and analyze social media data: a case study of the use of Twitter during the 2014 Euromaidan revolution in Ukraine. In: Sloan L, Quan-Haase A, editors. The SAGE Handbook of Social Media Research Methods. Thousand Oaks, CA: SAGE Publications; 2016:513-529.

66. Harder A, Howard V, Sedo DR. Creating cohesive community through shared reading: a case study of one book Nova Scotia. Partnership 2015 Jun 25;10(1):-. [doi: 10.21083/partnership.v10i1.3098]

67. Gruzd A, Haythornthwaite C. Enabling community through social media. J Med Internet Res 2013 Oct 31;15(10):e248 [FREE Full text] [doi: 10.2196/jmir.2796] [Medline: 24176835]

68. Murphy KL, Liu M, Herzog TA. Confirmatory factor analysis and structural equation modeling of socio-cultural constructs among chamorro and non-chamorro micronesian betel nut chewers. Ethn Health 2019 Aug;24(6):724-735. [doi: 10.1080/13557858.2017.1346177] [Medline: 28678534]

69. Croucher R, Islam S. Socio-economic aspects of areca nut use. Addict Biol 2002 Jan;7(1):139-146. [doi: 10.1080/13556210120091518] [Medline: 11900634]

70. Gupta PC, Warnakulasuriya S. Global epidemiology of areca nut usage. Addict Biol 2002 Jan;7(1):77-83. [doi: 10.1080/13556210020091437] [Medline: 11900626 ]

71. Hand M. Visuality in social media: researching images, circulations, and practices. In: Sloan L, Quan-Haase A, editors. The SAGE Handbook of Social Media Research Methods. Thousand Oaks, CA: SAGE Publications; 2016:215-231.

72. Joo YJ, Newcombe D, Nosa V, Bullen C. Investigating Betel Nut Use, Antecedents and Consequences: A Review of Literature. Subst Use Misuse 2020;55(9):1422-1442. [doi: 10.1080/10826084.2019.1666144] [Medline: 31549570]

73. Warnakulasuriya S. Areca nut use following migration and its consequences. Addict Biol 2002 Jan;7(1):127-132. [doi: 10.1080/13556210120091491] [Medline: 11900632]

74. Cavazos-Rehg PA, Krauss M, Fisher SL, Salyer P, Grucza RA, Bierut LJ. Twitter chatter about marijuana. J Adolesc Health 2015 Feb;56(2):139-145 [FREE Full text] [doi: 10.1016/j.jadohealth.2014.10.270] [Medline: 25620299]

75. Cotter K. Playing the visibility game: how digital influencers and algorithms negotiate influence on Instagram. New Media Soc 2019;21(4):895-913. [doi: 10.1177/1461444818815684]

\section{Abbreviations}

API: application programming interface

e-cigarettes: electronic cigarettes

e-juice: electronic juice

NIH: National Institutes of Health

NHPI: Native Hawaiian and Pacific Islanders

SCT: social cognitive theory

U\&G: uses and gratifications

USAPI: US-Affiliated Pacific Islands

Edited by G Eysenbach; submitted 07.03.19; peer-reviewed by JP Allem, MS Aslam; comments to author 09.12.19; revised version
received 27.04.20; accepted 30.04.20; published 09.07.20
Please cite as:
Buente W, Dalisay F, Pokhrel P, Kramer HK, Pagano I
An Instagram-Based Study to Understand Betel Nut Use Culture in Micronesia: Exploratory Content Analysis
J Med Internet Res $2020 ; 22(7):$ e13954
URL: $\underline{\text { https://www.jmir.org/2020/7/e13954 }}$
doi: $\underline{10.2196 / 13954}$
PMID: $\underline{32673220}$


(C) Wayne Buente, Francis Dalisay, Pallav Pokhrel, Hanae Kurihara Kramer, Ian Pagano. Originally published in the Journal of Medical Internet Research (http://www.jmir.org), 09.07.2020. This is an open-access article distributed under the terms of the Creative Commons Attribution License (https://creativecommons.org/licenses/by/4.0/), which permits unrestricted use, distribution, and reproduction in any medium, provided the original work, first published in the Journal of Medical Internet Research, is properly cited. The complete bibliographic information, a link to the original publication on http://www.jmir.org/, as well as this copyright and license information must be included. 